\title{
The Impact of Confinement on the Dynamics and H-bonding Pattern in Low-Molecular Weight Poly(propylene glycols)
}

\author{
Agnieszka Talik ${ }^{\dagger *}$, Magdalena Tarnacka ${ }^{\dagger *}$, Monika Geppert-Rybczyńska ${ }^{\S}$, Barbara \\ Hachuła $^{\S *}$, Kamil Kaminski ${ }^{\dagger *}$, Marian Paluch ${ }^{\dagger \neq}$ \\ † Institute of Physics, University of Silesia in Katowice, 75 Pulku Piechoty 1, 41-500 Chorzow, \\ Poland \\ \# Silesian Center of Education and Interdisciplinary Research, University of Silesia in \\ Katowice, 75 Pulku Piechoty 1A, 41-500 Chorzow, Poland \\ $\S$ Institute of Chemistry, University of Silesia in Katowice, Szkolna 9, 40-006 Katowice, Poland \\ * Corresponding authors: *(AT) e-mail: agnieszka.talik@smcebi.edu.pl; (BH) email: \\ barbara.hachula@us.edu.pl; (MT) email:magdalena.tarnacka@smcebi.edu.pl
}

\section{EXPERIMENTAL SECTION}

\section{Materials}

Native silica membranes were prepared as presented in Ref. ${ }^{1}$ by electrochemical etching of highly doped p-type $<100>$ oriented silicon wafers with resistivity $\leq 0.005 \Omega \mathrm{cm}$ and thermal oxidation at $1100 \mathrm{~K}$. A mixture of Hydrofluoric acid and Ethanol in the ratio of 1:1 was used as an electrolyte. Densities of $\mathrm{j}=20 \mathrm{mAcm}^{-1}$ were applied to obtain pore diameters of $d=4 \mathrm{~nm}$ with a porosity of 9-7\%. Thickness of used membranes is about $100 \pm 5 \mu \mathrm{m}$. Before filling the templates, they were annealed in high vacuum $\left(10^{-5} \mathrm{mbar}\right)$ at $470 \mathrm{~K}$ for $24 \mathrm{~h}$ to remove any volatile impurities.

Silanized $\mathrm{SiO}_{2}$ membranes were prepared using a mixture of methoxytrimethylsilane (TMMOS, with purity $96+\%$ purchased from Acros Organics) and hexane solvent in the ratio of 1:1 and then annealed at $323 \mathrm{~K}$ for $48 \mathrm{~h}$. By treating the membrane with TMMOS, the silanol groups 
Qwere replaced with trimethylsilyl groups, and the surface became more hydrophobic ${ }^{2}$. FTIR investigations allow estimating the degree of silanization to be around $95 \%$.

The nanoporous alumina oxide membranes used in this study were supplied from InRedox and composed of uniaxial channels (open from both side) with well- defined pore diameter, $\mathrm{d} \sim 18 \pm 2 \mathrm{~nm}$, thickness $\sim 50 \pm 2 \mu \mathrm{m}$ and porosity $\sim 12 \pm 2 \%$. Details concerning pore density, distribution, etc. can be found at the Webpage of the producer ${ }^{3}$. Additionally, dielectric and FTIR spectra as well as DSC thermograms collected for empty native and silanized silica pores of $d=4 \mathrm{~nm}$ are presented in Figure S1.
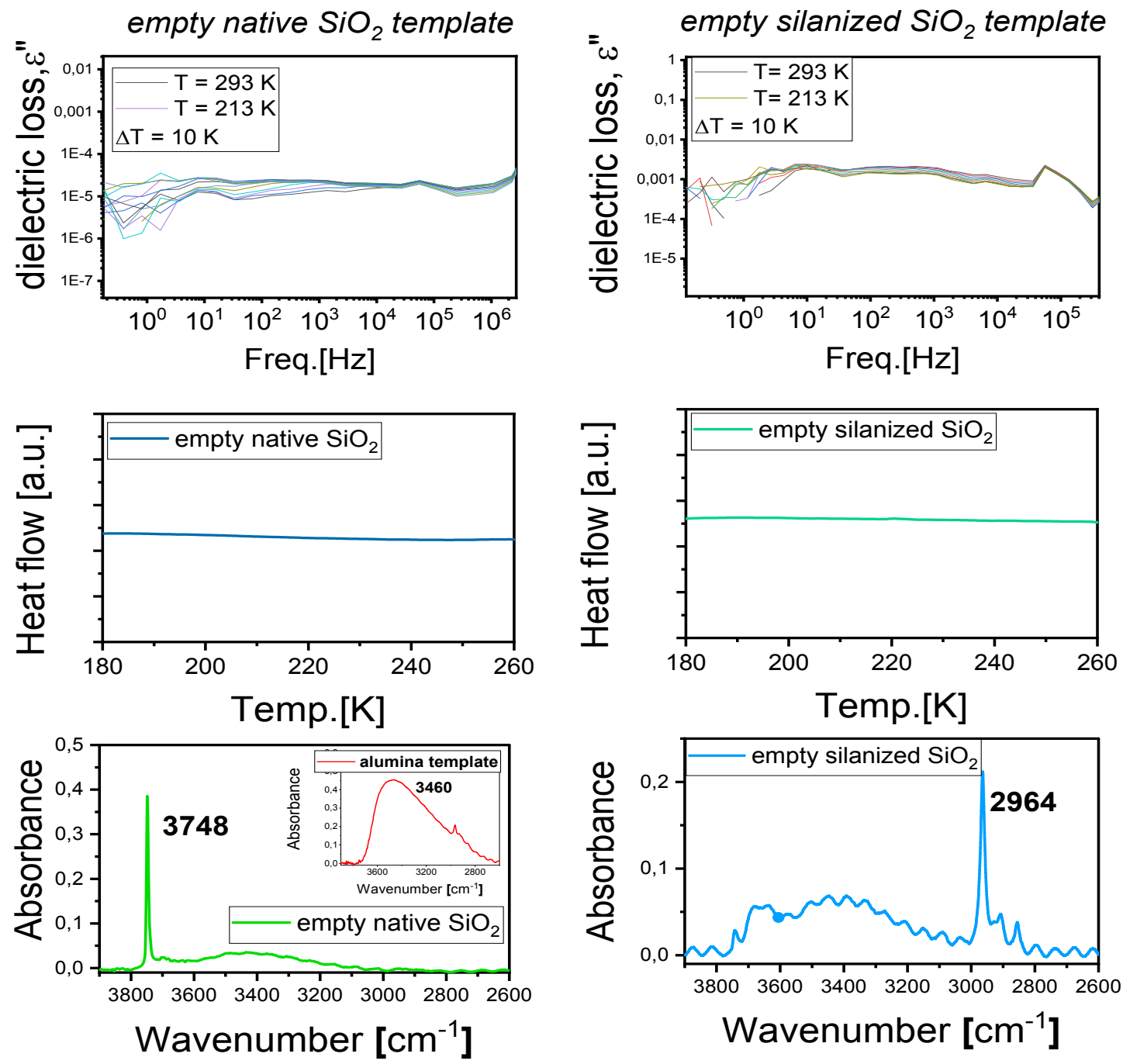

Figure S1. The Spectra of templates before filling obtained from BDS, DSC and FTIR (membranes in the 3900-2600 $\mathrm{cm}^{-1}$ spectral range) measurements for native and 
silanized silica pores $(d=4 \mathrm{~nm})$. As inset, infrared spectra of the alumina membranes in the $3900-2600 \mathrm{~cm}^{-1}$ spectral range.

\section{Methods}

\section{1. $\mathrm{N}_{2}$ adsorption/desorption isotherms.}

The porosity and pore diameter of $\mathrm{SiO}_{2}$ membranes of $\mathrm{d}=4 \mathrm{~nm}$ have been determined basing on the low temperature nitrogen adsorption/desorption isotherms measured at $77 \mathrm{~K}$ by using automatic ASAP 2020 sorption analyzer (Micromeritics Instrument Corp., USA). Prior to the measurement, the established amount $(0.18 \mathrm{~g})$ of $\mathrm{SiO}_{2}(\mathrm{~d}=4 \mathrm{~nm})$ support was outgassed $(2 \mu \mathrm{mHg})$ at $453 \mathrm{~K}$ for $48 \mathrm{~h}$ under vacuum in the degas port of the sorption analyzer. The obtained adsorption/desorption isotherms were used to evaluate the structure of the studied material. Data analysis was assessed by means of MicroActive software (Micromeritics). The calculations of the pore size distribution (PSD), and the average $\mathrm{BJH}$ desorption pore diameter $\left(D_{\mathrm{av}, \mathrm{des}}\right)$ and the maximum pore diameter $\left(D_{\text {mo,des }}\right)$ were obtained from the desorption branches of the nitrogen isotherm by means of the Barrett-Joyner-Halenda $(\mathrm{BJH})$ procedure for cylinder pores with Halsey-Faas correction without smooth differentials ${ }^{4}$. The experimental nitrogen adsorption/desorption isotherms and pore-size distribution (PSD) function calculated from desorption branch of isotherm for investigated sample are illustrated in Figure S2 (a). The pore size distribution (PSD) curve for $\mathrm{SiO}_{2}$ of $\mathrm{d}=4 \mathrm{~nm}$ was estimated from the desorption branch of nitrogen isotherm using the Barrett-Joyner-Halenda $(\mathrm{BJH})$ model with cylindrical pores (Figure S2 (b)). The PSD plot for the investigated material shows relatively narrow pore sizes distribution suggesting that porous structure is fairly uniform; the pores diameter is about $D_{\mathrm{av}, \text { des }}$ $\sim 4.27 \mathrm{~nm}, D_{\text {mo,des }} \sim 4.50$. For characterization of $\mathrm{SiO}_{2}$ nanopores scanning electron microscopy (SEM) measurements were taken from Ref. ${ }^{5}$, see Figure S2 (c). 

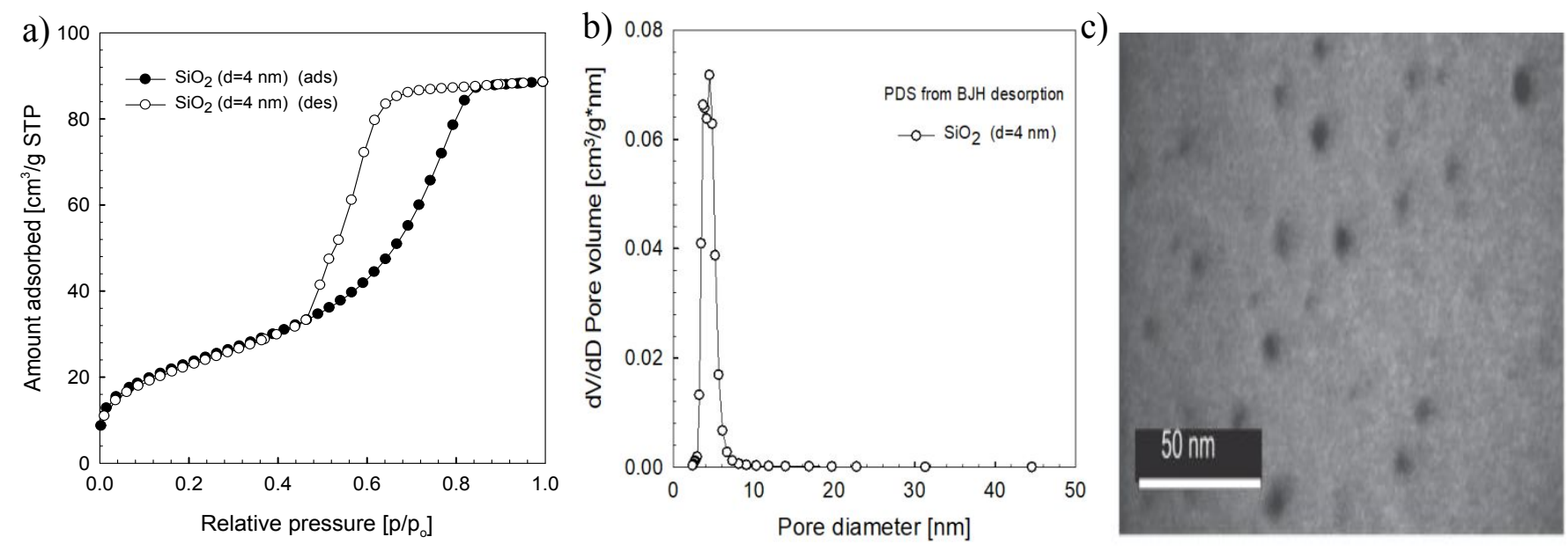

Figure S2. (a) Nitrogen adsorption/desorption isotherms for $\mathrm{SiO}_{2}$ material (d=4 nm); (b) Pore size distribution (PSD) for $\mathrm{SiO}_{2}(d=4 \mathrm{~nm})$ calculated from desorption branches of isotherm ; (c) Scanning electron microscope (SEM) images for $\mathrm{SiO}_{2}$ of $\mathrm{d}=4 \mathrm{~nm}$ taken from Ref. 5 .

\section{RESULTS}
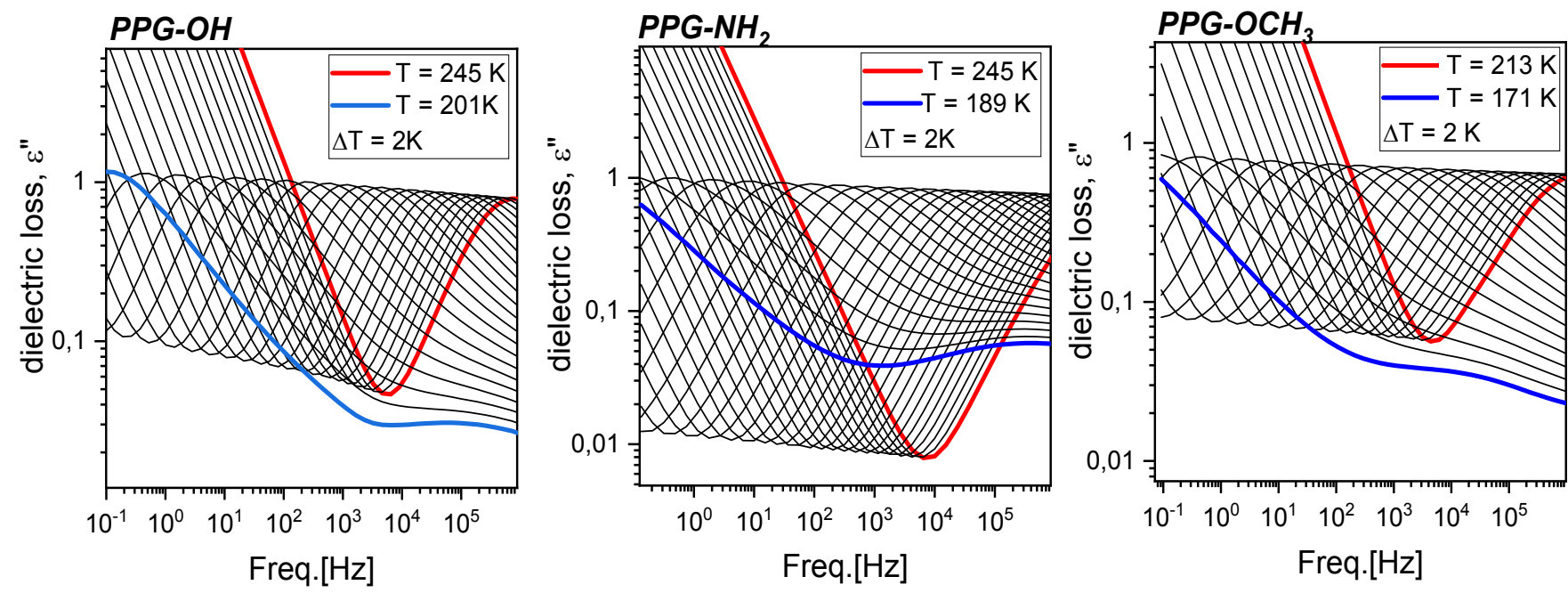

Figure S3. Dielectric loss spectra for bulk PPG's taken from Ref.6 

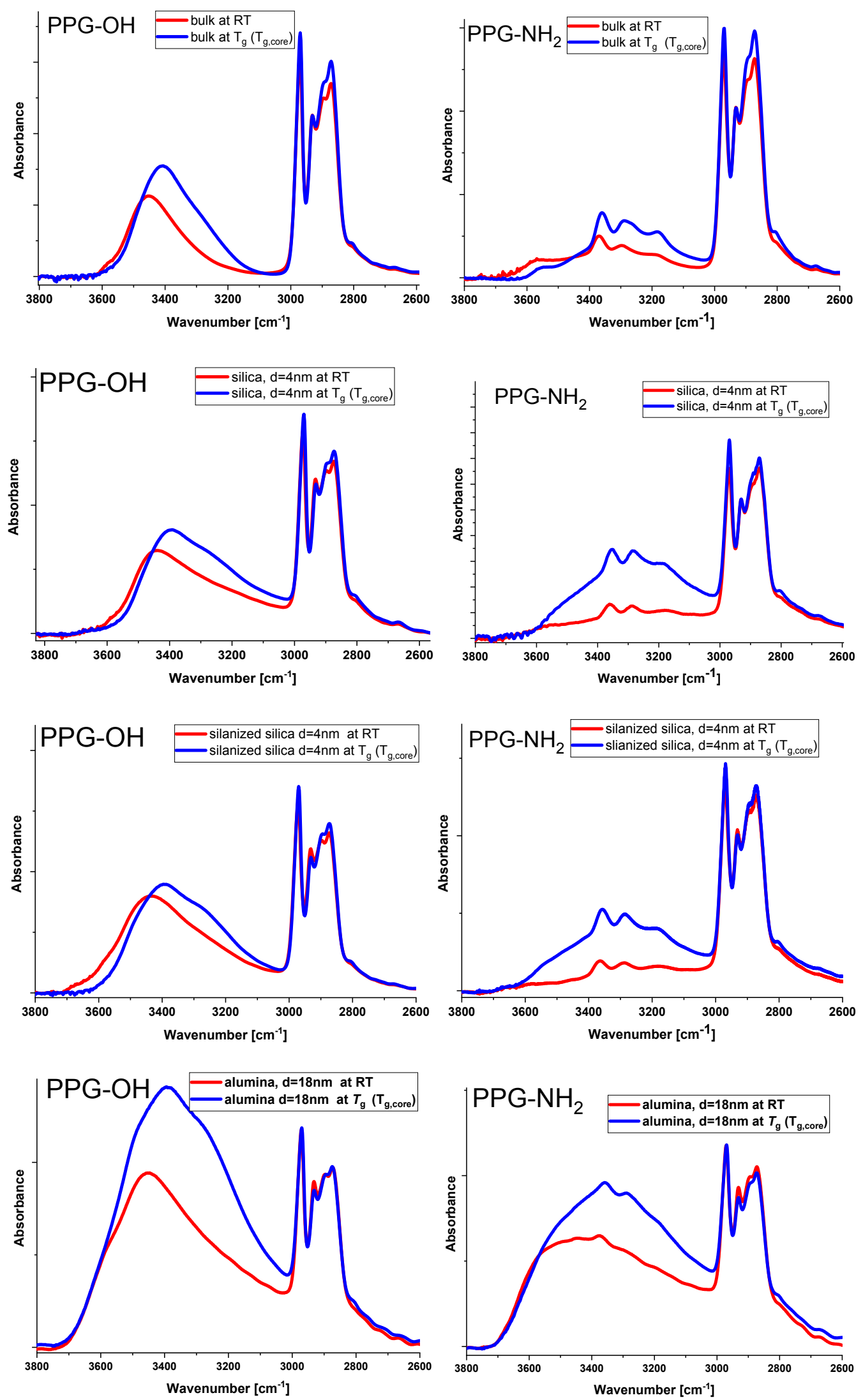

Figure S4. FTIR spectra of bulk and confined PPGs samples within the native silica, silanized silica and alumina pores recorded in the frequency range of $3800-2600 \mathrm{~cm}^{-1}$ measured at room 
temperature (red) and the glass transition temperature (blue). The spectra were normalized to the C-H absorption peak at around $2970 \mathrm{~cm}^{-1}$.

The shift towards lower wavenumbers and the corresponding growth of integral intensity of the $\mathrm{v}_{\mathrm{X}-\mathrm{H}}$ bands is related to the weakening of the $\mathrm{X}-\mathrm{H}$ bonds, due to an increase of the hydrogen-bond strength, and to the increase of the population of H-bonded aggregates of PPGs molecules, respectively. At $T_{\mathrm{g}}$, the $\mathrm{v}_{\mathrm{X}-\mathrm{H}}$ peaks are located at 3407 and 3360,3289 , $3184 \mathrm{~cm}^{-1}$ for PPG-OH and PPG-NH$H_{2}$, respectively $\left(\Delta \mathrm{v}=46 \mathrm{~cm}^{-1}\right.$ for PPG-OH; $\Delta \mathrm{v}=9,9,17$ $\mathrm{cm}^{-1}$ for PPG-NH${ }_{2}$ ) (see Figure S4). Also, the half-bandwidths of the $\mathrm{v}_{\mathrm{X}-\mathrm{H}}$ bands are influenced by the effect of temperature i.e. this spectral parameter increases with temperature drop. Therefore, at lower temperature the larger heterogeneity among the hydrogen-bonded moieties of the bulk samples exists.

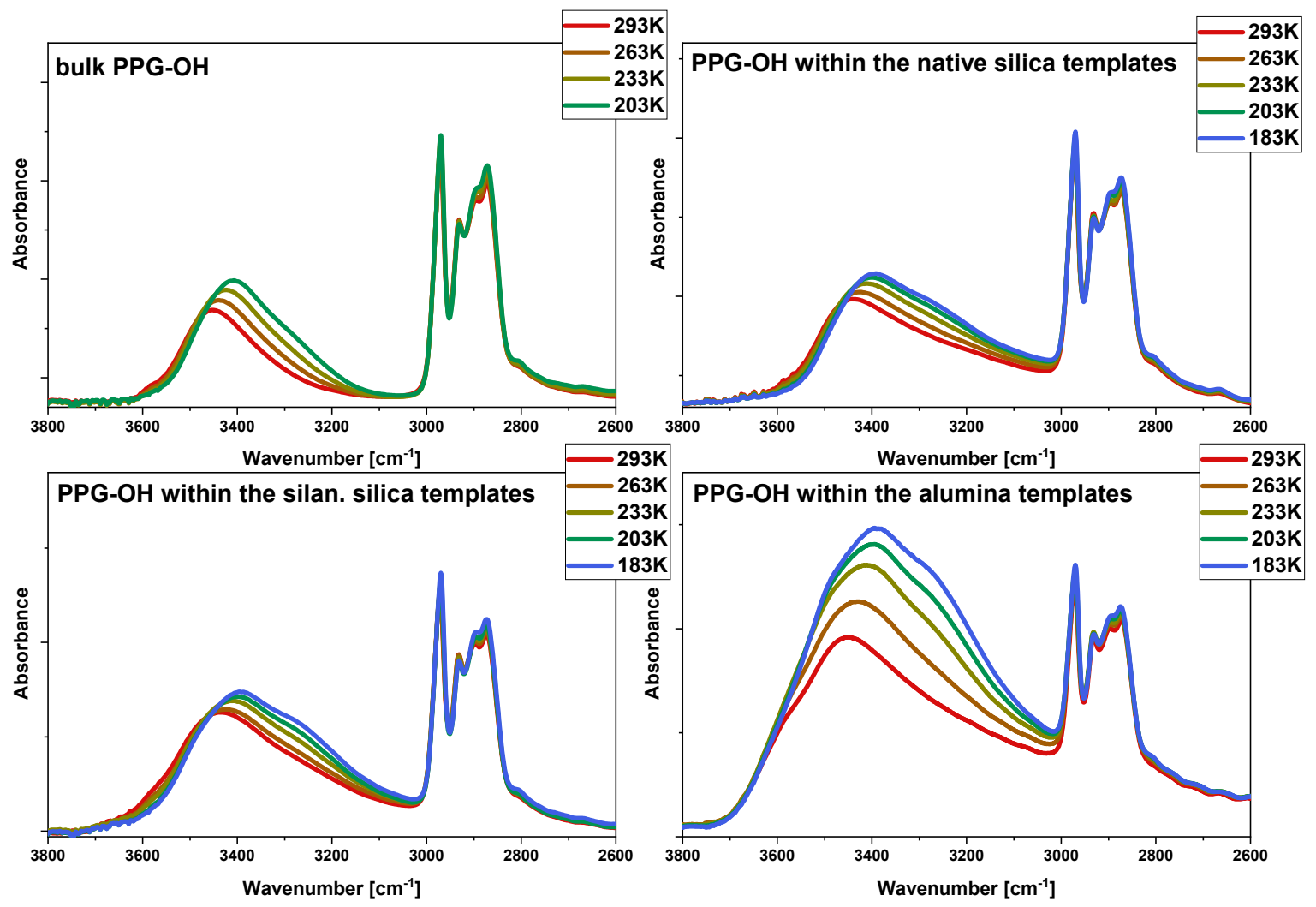

Figure S5. FTIR spectra of bulk and confined PPG-OH in the spectral region of 2600-3800 
$\mathrm{cm}^{-1}$ in the selected temperatures (bulk: 293K, 263K, 233K, 203K; confined: $293 \mathrm{~K}, 263 \mathrm{~K}$, $233 \mathrm{~K}, 203 \mathrm{~K}, 183 \mathrm{~K})$.
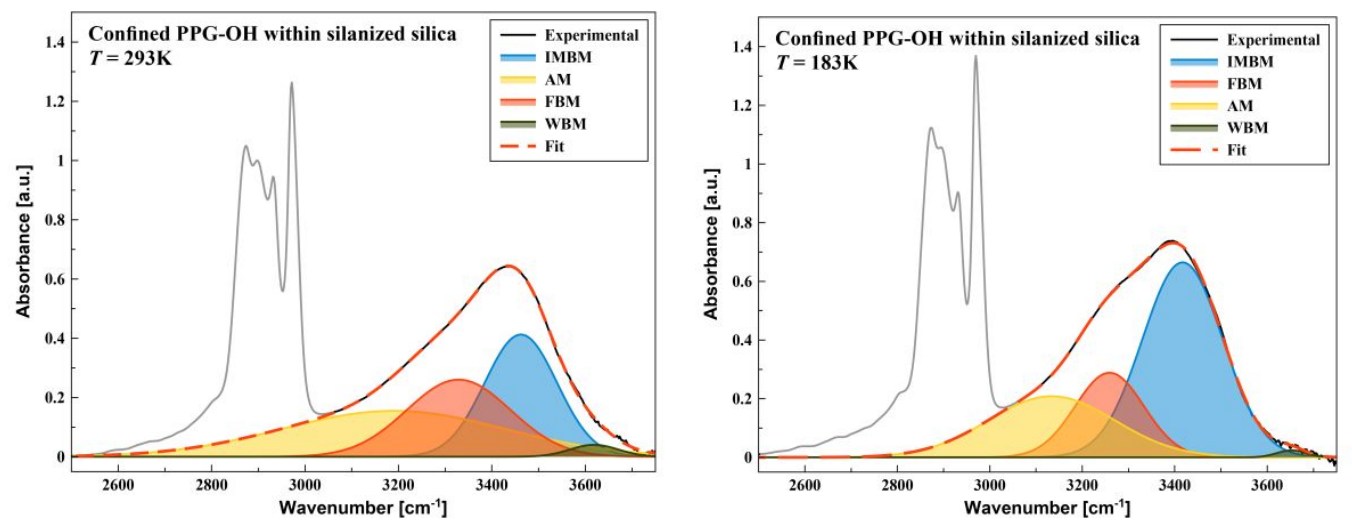

Figure S6. Decomposition of the $v_{\mathrm{OH}}$ band of confined PPG-OH within silanized silica templates in the frequency range of 2500 and $3750 \mathrm{~cm}^{-1}$ in the temperatures of $293 \mathrm{~K}$ and $183 \mathrm{~K}$.

\begin{tabular}{|c|c|c|c|c|c|c|c|c|}
\hline$T[K]$ & $\begin{array}{l}v_{O H}^{A M} \\
{\left[\mathrm{~cm}^{-1}\right]}\end{array}$ & $\begin{array}{l}I_{O H}^{A M} \\
\text { [a.u.] }\end{array}$ & $\begin{array}{l}v_{O H}^{F B M} \\
{\left[\mathrm{~cm}^{-1}\right]}\end{array}$ & $\begin{array}{l}I_{O H}^{F B M} \\
\text { [a.u.] }\end{array}$ & $\begin{array}{l}v_{O H}^{I M B M} \\
{\left[\mathrm{~cm}^{-1}\right]}\end{array}$ & $\begin{array}{l}I M B M \\
I_{O H}^{I M B} \\
\text { [a.u.] }\end{array}$ & $\begin{array}{l}v_{O H}^{W B M} \\
{\left[\mathrm{~cm}^{-1}\right]}\end{array}$ & $\begin{array}{l}I_{O H}^{W B M} \\
\text { [a.u.] }\end{array}$ \\
\hline \multicolumn{9}{|c|}{ bulk PPG-OH } \\
\hline 293 & & & 3363,77 & 46,49 & 3459,14 & 50,69 & 3585,45 & 0,56 \\
\hline 263 & & & 3350,51 & 57,22 & 3450,78 & 55,09 & 3583,42 & 0,34 \\
\hline 233 & & & 3344,03 & 71,79 & 3443,12 & 55,89 & 3583,93 & 0,36 \\
\hline 203 & & & 3335,03 & 89,87 & 3432,95 & 54,55 & 3589,09 & 0,39 \\
\hline \multicolumn{9}{|c|}{ confined PPG-OH within native silica templates } \\
\hline 293 & 3194,52 & 137,36 & 3393,04 & 85,15 & 3463,29 & 36,46 & 3606,62 & 1,98 \\
\hline 263 & 3146,29 & 115,89 & 3362,64 & 105,14 & 3454,77 & 52,59 & 3618,46 & 3,58 \\
\hline 233 & 3111,9 & 111,65 & 3333,84 & 117,21 & 3445,17 & 69,93 & 3619,08 & 3,22 \\
\hline 203 & 3073,83 & 178,24 & 3318,22 & 119,78 & 3433,69 & 66,33 & 3648,67 & 2,59 \\
\hline 183 & 3073,43 & 217,24 & 3305,97 & 112,44 & 3427,59 & 69,83 & 3656,03 & 1,31 \\
\hline \multicolumn{9}{|c|}{ confined PPG-OH within silanized silica templates } \\
\hline 293 & 3189,76 & 95,72 & 3328,95 & 72,44 & 3462,12 & 79,98 & 3618,88 & 5,21 \\
\hline 263 & 3171,29 & 108,80 & 3328,18 & 87,59 & 3454,22 & 68,89 & 3616,85 & 2,89 \\
\hline 233 & 3127,54 & 63,83 & 3282,16 & 64,51 & 3437,59 & 123,67 & 3640,53 & 4,59 \\
\hline 203 & 3127,67 & 60,00 & 3265,17 & 57,09 & 3423,13 & 139,07 & 3647,78 & 1,75 \\
\hline 183 & 3133,73 & 71,29 & 3258,94 & 53,59 & 3416,96 & 144,73 & 3652,55 & 1,89 \\
\hline \multicolumn{9}{|c|}{ confined PPG-OH within alumina templates } \\
\hline 293 & 3197,97 & 212,18 & 3361,35 & 84,00 & 3482,48 & 98,60 & 3603,24 & 17,83 \\
\hline 263 & 3167,53 & 235,03 & 3339,15 & 125,19 & 3473,58 & 126,59 & 3594,87 & 20,01 \\
\hline 233 & 3143,43 & 238,01 & 3319,33 & 167,97 & 3463,96 & 151,11 & 3581,22 & 30,19 \\
\hline 203 & 3095,95 & 196,22 & 3291,44 & 183,07 & 3453,42 & 205,89 & 3578,38 & 33,19 \\
\hline
\end{tabular}




\begin{tabular}{|l|l|l|l|l|l|l|l|l|}
\hline 183 & 3026,01 & 154,14 & 3293,60 & 278,29 & 3460,08 & 200,11 & 3586,75 & 23,87 \\
\hline
\end{tabular}

Table S1. Best-fit parameters (the peak position $v$ and the peak area $I$ ) of the $\mathrm{OH}$ stretching band for bulk and confined PPG-OH.

\begin{tabular}{|l|c|c|c|c|}
\hline T [K] & AM [\%] & FBM [\%] & IMBM [\%] & WBM [\%] \\
\hline \multicolumn{5}{|c|}{ bulk PPG-OH } \\
\hline 293 & & 47,56 & 51,86 & 0,58 \\
\hline 263 & & 50,79 & 48,90 & 0,31 \\
\hline 233 & & 56,07 & 43,65 & 0,28 \\
\hline 203 & 62,06 & 37,67 & 0,27 \\
\hline \multicolumn{5}{|c|}{ confined PPG-OH within native silica templates } \\
\hline 293 & 52,64 & 32,63 & 13,97 & 0,76 \\
\hline 263 & 41,81 & 37,93 & 18,97 & 1,29 \\
\hline 233 & 36,97 & 38,81 & 23,15 & 1,07 \\
\hline 203 & 48,58 & 32,64 & 18,07 & 0,71 \\
\hline 183 & 54,20 & 28,05 & 17,42 & 0,33 \\
\hline \multicolumn{5}{|c|}{ confined PPG-OH within silanized silica templates } \\
\hline 293 & 37,78 & 28,59 & 31,57 & 2,06 \\
\hline 263 & 40,57 & 32,66 & 25,69 & 1,08 \\
\hline 233 & 24,87 & 25,14 & 48,19 & 1,80 \\
\hline 203 & 23,26 & 22,13 & 53,92 & 0,68 \\
\hline 183 & 26,26 & 19,74 & 53,31 & 0,69 \\
\hline \multicolumn{5}{|c|}{ confined PPG-OH within alumina templates } \\
\hline 293 & 51,42 & 20,36 & 23,89 & 4,33 \\
\hline
\end{tabular}




\begin{tabular}{|l|l|l|l|l|}
\hline 263 & 46,37 & 24,70 & 24,98 & 3,95 \\
\hline 233 & 40,53 & 28,60 & 25,73 & 5,14 \\
\hline 203 & 31,73 & 29,60 & 33,29 & 5,38 \\
\hline 183 & 23,48 & 42,40 & 30,48 & 3,64 \\
\hline
\end{tabular}

Table S2. Ratio of the $v_{\mathrm{OH}}$ peak area obtained from spectral fittings for bulk and confined PPG-OH.
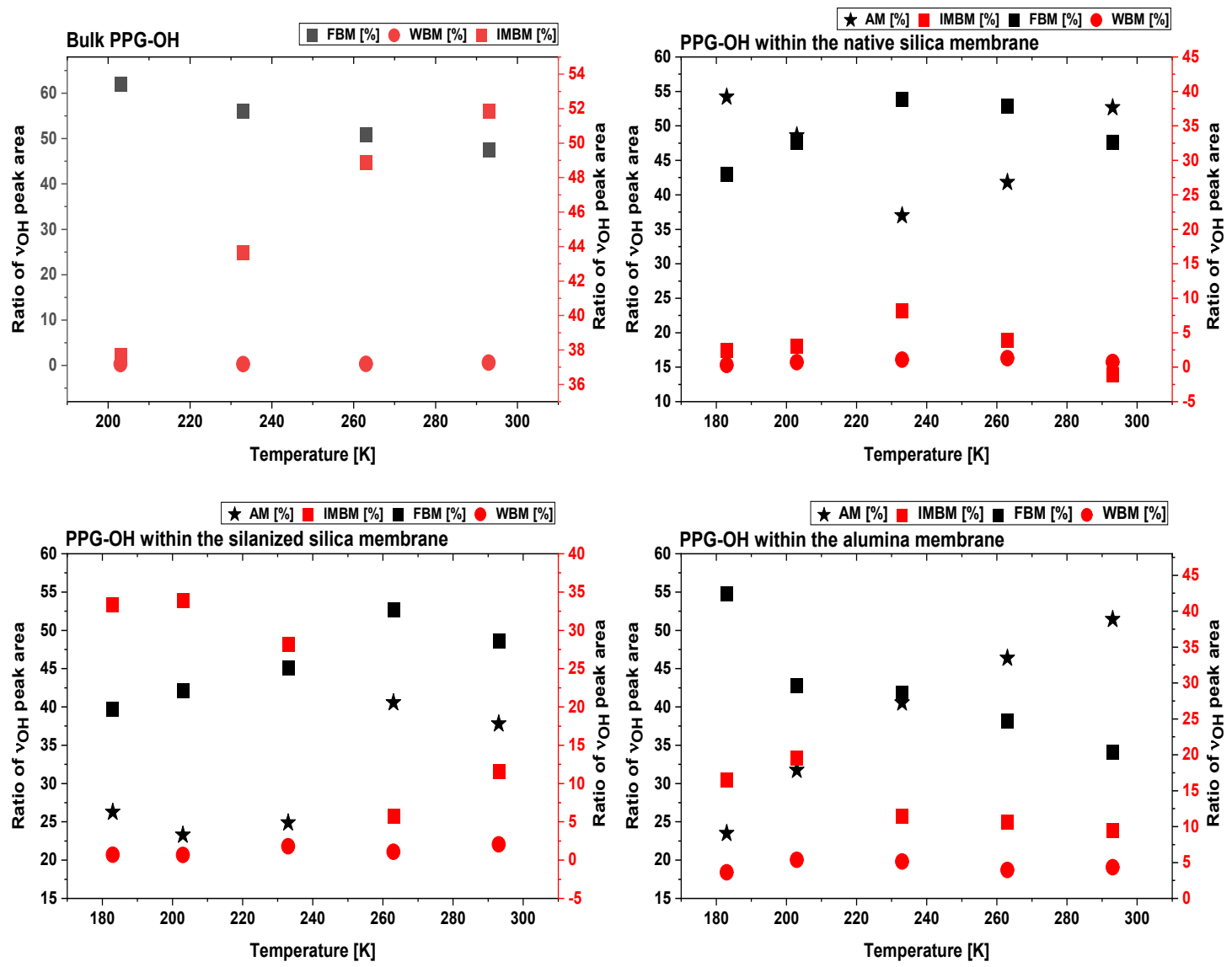

Figure S7. The temperature evolution of peak areas obtained from the fitting of the -OH band of bulk and confined PPG-OH by the superposition of the few Gaussian functions assigned to vibration of this moiety in the following fractions of oligomers AM, IMBM,FBM,WBM. 


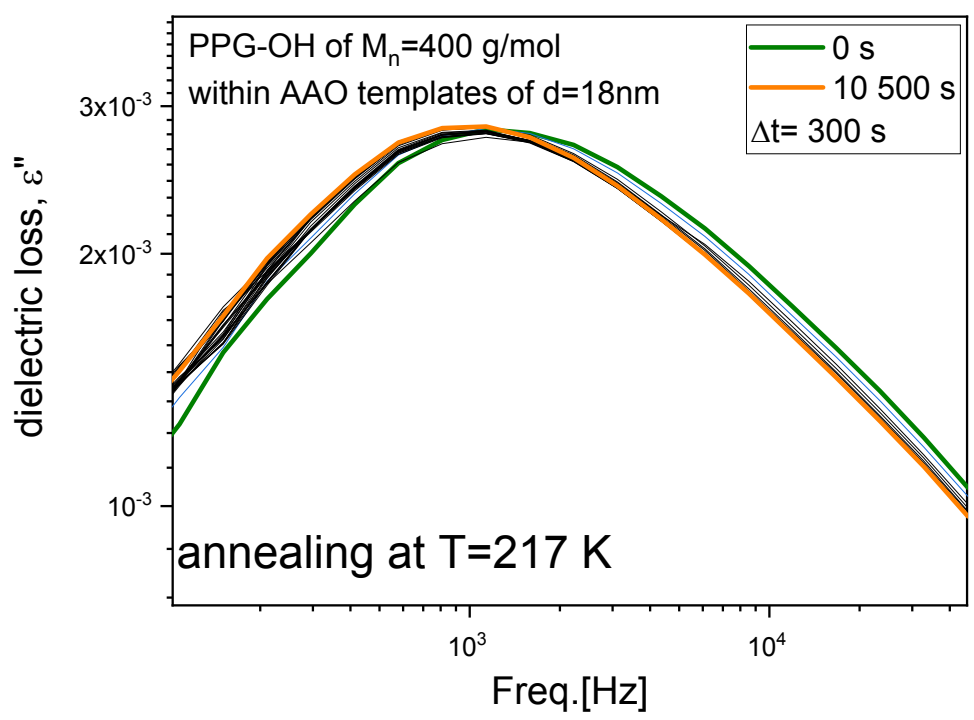

Figure S8. Dielectric loss spectra collected upon annealing of confined samples at $\mathrm{T}=217$ $\mathrm{K}$ measured for PPG-OH of $\mathrm{M}_{\mathrm{n}}=400 \mathrm{~g} / \mathrm{mol}$ confined in AAO templates of $d=18 \mathrm{~nm}$ taken from Ref.6.

\section{References:}

1. Kipnusu, W. K.; Kossack, W.; Iacob, C.; Jasiurkowska, M.; Sangoro, J.R.; Kremer, F. Molecular Order and Dynamics of Tris(2- ethylhexyl)phosphate Confined in Uni-Directional Nanopores. Z. Phys. Chem. 2012, 226, 797-805.

2. Iacob, C.; Sangoro, J.R.; Papadopoulos, P.; Schubert, T.; Naumov, S.; Valiullin, R.; Karger, J.; Kremer, F. Charge Transport andDiffusion of Ionic Liquids in Nanoporous Silica Membranes. Phys. Chem. Chem. Phys. 2010, 12, 13798-13803.

3. https://www.inredox.com

4. Barrett, E.P.; Joyn, L.G.; Halenda, P.P. The determination of pore volume and area distributions in porous substances. I. Computations from nitrogen isotherms. J. Am. Chem. Soc. 1951, 73, 373-80.

5. Iacob, C.; Sangoro, J.R.; Kipnusu, W.K.; Valiullin, R.; Kärger, J.; Kremer, F. Enhanced charge transport in nano-confined ionic liquids. Soft Matter, 2012, 8(2), 289-293.

6. Tarnacka, M.; Talik, A.; Kamińska, E.; Geppert-Rybczyńska, M.; Kaminski, K.; Paluch, M. The Impact of Molecular Weight on the Behavior of Poly(propylene glycols) Derivatives Confined within Alumina Templates. Macromolecules 2019, 52 (9), 3516-3529. 